\title{
Correlation between CTLA-4 and CD40 gene polymorphisms and their interaction in graves' disease in a Chinese Han population
}

Xiaoming Chen ${ }^{\dagger}$, Zhuoqing Hư ${ }^{\dagger}$, Meilian Liu, Huaqian Li, Chanbo Liang, Wei Li, Liwen Bao, Manyang Chen and Ge Wu ${ }^{*}(\mathbb{D}$

\begin{abstract}
Background: Single-nucleotide polymorphism (SNP) haplotype and SNP-SNP interactions of CTLA-4 and CD40 genes, with susceptibility to Graves' disease (GD), were explored in a Chinese Han population.

Methods: SNP were genotyped by high resolution melting (HRM). Use the method of Pearson $x 2$ test and Logistic regression for the association between single SNP and Graves' disease. Using the method of X2 test and Multifactor Dimensionality Reduction (MDR) to analysis the haplotype frequency distribution, the interaction of SNPs respectively.

Results: Genotypic and allelic frequencies of SNP rs231775, rs3087243 and rs1883832 were statistically different between controls and GD $(p<0.05)$. Mutant allelic frequency of $\mathrm{G}$ rs 231775 was higher, and $\mathrm{A}$ and $\mathrm{T}$ allelic frequencies of rs3087243 and rs 1883832 were lower in GD than in controls $(P<0.05)$. In CTLA-4 rs 1024161, rs5742909, rs231775, rs231777, rs231779, rs3087243 and rs 11571319 showed $D^{\prime}<50 \%$ and $r^{2}<0.3$ among each SNP. We identified six commonly found haplotypes; TCGCTGC was associated with the highest GD risk $(O R=2.565)$ and TCACTAC the lowest $(O R=0.096)$. MDR analysis indicated interactions among the rs 231775 GG, rs231779 TT and rs3087243 GG genotypes in CTLA-4 might increase $\mathrm{GD}$ risk by 2.53 -fold $(O R=2.53)$.
\end{abstract}

Conclusion: CTLA-4 and CD40 were associated with GD incidence in a Chinese Han population. The TCGCTGC and TCAC TAC haplotypes in the CTLA-4 gene, were risk and protective factors for Graves'disease respectively. Interactions among the SNPs of rs231775, rs231779 and rs3087243 significantly increase the susceptibility to GD.

Keywords: Graves' disease, CD40, CTLA-4, Genetic polymorphism

\section{Background}

As a thyroid-specific autoimmune disease, Graves' disease (GD) is the most common cause of hyperthyroidism. The pathogenesis of GD is unclear; however, genome-wide association studies (GWAS) indicate that the genetic background of GD is decided by several genes with differential penetrance. Moreover, GD is a complex disease that is associated with gene-gene and gene-environment interactions $[1,2]$. Interactions between costimulatory molecules and downstream cytokines (such as IL-2) that are

\footnotetext{
* Correspondence: wuge427427@126.com

${ }^{+}$Xiaoming Chen and Zhuoqing Hu contributed equally to this work. Department of Endocrinology, Affiliated Hospital of Guangdong Medical University, Zhanjiang 524001, China
}

regulated by $\mathrm{CD} 28$ (CTLA-4)/B7 and CD40/CD40L are important mechanisms that constitute the immune response. Studies show that abnormalities of these common signaling pathways are associated with multiple autoimmune diseases (AID) such as diabetes, scleroderma and autoimmune thyroid disease [3]. Correlations between CTLA-4 and GD susceptibility are complex, wherein mutations play a significant role, and specific sites in those mutations are both unstable and correlated with GD in different populations [4-7]. For instance, the +49A/G polymorphism in exon 1 results in a threonine-to-alanine conversion, which $\mathrm{Gu}$ et al. showed to be associated with GD in the Chinese Han population [5]. By contrast, others found that the $+49 \mathrm{~A} / \mathrm{G}$ polymorphism in exon 1 was 
irrelevant in the Japanese, Brazil and Lebanese populations $[4,6,7]$. Linkage analysis, candidate gene analysis and GWAS unanimously confirmed that the CD40-1 C/T polymorphism located at 20q11.2-20q13 was stably associated with GD susceptibility [8-10]. The Kozak consensus sequence is a necessary nucleotide fragment in the initiation of translation of CD40, while the CC genotype and allele $\mathrm{C}$ can both increase mRNA translation efficiency of the CD40 gene and thus increase its expression by $15-32 \%[11,12]$.

There are very many genetic mutations and sophisticated haplotype models in the CTLA-4 and CD40 genes, whose correlation with particular disease states are far more complex than had originally been appreciated. A recent study showed that there may be a combined and additive effect between the CD40-1C > T and CTLA-4-6230G > A polymorphisms with the development of GD [13]. Thus, we have combined multiple known polymorphic loci before performing correlation analyses between the haplotypes and GD. The over-arching objective of this approach was to provide a more accurate genetic exploration of the susceptibility of GD. In addition, we present an in-depth analysis of the correlation between CTLA-4 and CD4O genes against GD susceptibility via interaction analysis of CTLA-4 and CD40 in cases of GD as compared with a control population.

\section{Methods}

\section{Subjects and grouping}

This was a retrospective analysis of data that were collected from 260 GD patients (48 males and 212 females, with a mean age of $36.2 \pm 15.2$ years) from the outpatient or inpatient departments of Endocrinology of the Affiliated Hospital of Guangdong Medical University between June 2013 and June 2014 (specific data are shown in Table 1).

The inclusion criteria for the patients with GD were based upon the clinical diagnostic criteria of GD in the Internal Medicine manual (8th edition, People's Medical publishing house) as follows: (1) The patients met the clinical diagnostic criteria of GD. (2) Patients without

Table 1 Basic clinical characteristics of the subjects

\begin{tabular}{llll}
\hline & GD group & Control & $p$ value \\
\hline Sex (male/female) & $48 / 212$ & $104 / 144$ & 0.001 \\
Age (years) & $36.2 \pm 15.2$ & $37.4 \pm 11.3$ & 0.263 \\
FT3 (pmol/L) & $13.28 \pm 13.12$ & $4.38 \pm 3.61$ & $<0.0001$ \\
FT4 (pmol/L) & $31.53 \pm 28.10$ & $16.33 \pm 3.61$ & $<0.0001$ \\
TSH (mUL/L) & $3.02 \pm 8.72$ & $2.07 \pm 1.11$ & $<0.0001$ \\
TRAb (IU/L) & $13.55 \pm 14.01$ & $0.51 \pm 0.50$ & $<0.0001$ \\
\hline
\end{tabular}

Note: Variants are expressed as mean \pm standard deviation $(\mathrm{M} \pm \mathrm{SD})$ or $\mathrm{N} ; F T 3$ free T3; FT4 free T4; TSH thyroid-stimulating hormone; TRAb TSH-receptor antibody; GD Graves' Disease other serious diseases, such as hypertension, malignancy, chronic liver and kidney diseases. (3) The subjects and other immediate family members over three generations had no autoimmune diseases except GD. (4) Three generations of the patients' family were of Han nationality and were resident in Western Guangdong.

Over the same period, 248 healthy volunteers (104 males and 144 females, with a mean age of $37.4 \pm$ 11.3 years) were selected as the normal control group. The healthy control group consisted of healthy individuals who underwent physical examination in the Affiliated Hospital of Guangdong Medical University during the same period. The inclusion criteria for the healthy control group were as follows: (1) There was no abnormality in medical history, physical examination, blood glucose examination, blood pressure, blood lipids and other biochemical tests through inquiry. (2) The subjects and other immediate family members over three generations had no autoimmune diseases including GD.

The exclusion criteria in both the GD case group and the healthy control group were as follows: (1) Inability to extract enough DNA to perform the classification experiment due to coagulation in serum sample. For example, improper storage of blood samples, improper transportation of blood samples as well as anticoagulation tube-induced coagulation. (2) There was a serious lack of information or serious information bias for the subject scale. (3) GD patients, controls, or other immediate family members in three generations had other autoimmune diseases except for GD.

Ethical approval was obtained from the Medical Ethics Committee of the Affiliated Hospital of Guangdong Medical University. The approval number was: PJ2012029. All the above enrolled patients signed an informed consent document.

\section{SNP genotyping}

The CTLA-4 SNPs (with a minor allele frequency $\leq 5 \%$, to exclude rare mutations from the analysis) covering the exons, introns, 5'-UTR, and 3'-UTR were selected. The SNP rs1024161 in the non-encoding area between CTLA-4 and KRT18P39 genes, and the CD40-1C/T polymorphic loci (rs1883832) were also selected. The PCR-HRM curve was used to genotype SNPs, adopting a $10-\mu \mathrm{l}$ PCR reaction assay system containing $5 \mu \mathrm{l}$ Premix $\mathrm{Taq}^{\mathrm{Tm}}, 0.2 \mu \mathrm{M}$ of each primer, $50 \mathrm{ng}$ DNA, and sterile water. The following reaction conditions were applied: 3 min denaturation at $94{ }^{\circ} \mathrm{C}$, followed by 30 cycles of a denaturation step $\left(30 \mathrm{~s}\right.$ at $\left.94{ }^{\circ} \mathrm{C}\right)$, an annealing step (30 s at the $\mathrm{Tm}$ annealing temperature), and an elongation step $\left(30 \mathrm{~s}\right.$ at $\left.72{ }^{\circ} \mathrm{C}\right)$, and a final elongation reaction at $72{ }^{\circ} \mathrm{C}$ for $10 \mathrm{~min}$. Table 2 lists the PCR primers and Tm values of each SNP. Following the manufacturer's instructions, a Lightscanner 96 (LS96, Idaho Technology 
Table 2 SNP PCR primers

\begin{tabular}{|c|c|c|c|}
\hline SNP & Primer & Size (bp) & $\operatorname{Tm}\left({ }^{\circ} \mathrm{C}\right)$ \\
\hline rs1024161 & $\begin{array}{l}\text { F:AGAAATTGGAGTTAAAGGCTCT } \\
\text { R:GAATGTACAGATAATGTCACTCT }\end{array}$ & 102 & 53 \\
\hline rs5742909 & $\begin{array}{l}\text { F:CTCCAAGTCTCCACTTAGTT } \\
\text { R:GAAGCTTCATGTTCACTIT }\end{array}$ & 51 & 53 \\
\hline rs231775 & $\begin{array}{l}\text { F:CCTTGGATTTCAGCGGCAC } \\
\text { R:AGAGTGCAGGGCCAGGT }\end{array}$ & 63 & 59.7 \\
\hline rs231777 & $\begin{array}{l}\text { F:ATTGAATCTCAACCTTATCTCTCTC } \\
\text { R:ACCTACTTCATACAAACTACATGG }\end{array}$ & 70 & 56.2 \\
\hline rs231779 & $\begin{array}{l}\text { F:TGCAGCCACTATTITGGAGTTGA } \\
\text { R:ACACTCCCATGCTCCTITGT }\end{array}$ & 96 & 59.2 \\
\hline rs3087243 & $\begin{array}{l}\text { F:TTCACCACTATTTGGGATATAA } \\
\text { R:GTGTTAAACAGCATGCCAAT }\end{array}$ & 80 & 53 \\
\hline rs11571319 & $\begin{array}{l}\text { F:TGGGTTAACACAGACATA } \\
\text { R:CCTGTGTTAAACAGCATGCCA }\end{array}$ & 59 & 50.5 \\
\hline rs11571302 & $\begin{array}{l}\text { F:ATGGGTTGTTCCACGACTTC } \\
\text { R:AAACGCTGCCAATAAACAGTC }\end{array}$ & 76 & 57 \\
\hline rs11571297 & $\begin{array}{l}\text { F:TTACTITAAACTTCCATTCCCAGC } \\
\text { R:TCTACCAGAAGTTGAAGTGTAGG }\end{array}$ & 82 & 57.3 \\
\hline rs1883832 & $\begin{array}{l}\text { F:CTGCCGCCTGGTCTCAC } \\
\text { R:ACTGCAGAGGCAGACGAAC }\end{array}$ & 45 & 60 \\
\hline
\end{tabular}

Inc.) was used to scan the reacted 96-well plate and record the data. The HRM-High and HRM-Low Tm internal calibrations were synthesized by Sangon Biotech (Shanghai, China). The sequences were as follows:

HRM-High Tm internal calibration sequence:

GCGGTCAGTCGGCCTAGCGGTAGCCAGCTGCG GCACTGCGTGACGCTCAG.

HRM-Low Tm internal calibration sequence: CTGAGCGTCACGCAGTGCCGCAGCTGGCTACC GCTAGGCCGACTGACCGC.

\section{Statistical analysis}

Quantitative data were expressed as mean \pm standard deviation $(M \pm S D)$, while qualitative data were expressed as frequency or percentage. When the data were not normally distributed, they were compared after being converted by the appropriate conversion functions. Independent samples between two groups were analyzed by the Student's T-test, while comparisons of independent samples among three or more groups were assessed by analysis of variance using SPSS 22.0 (IBM Corp., NY, USA). The Pearson's goodness-of-fit test, i.e., the Hardy-Weinberg equilibrium equation was adopted. The robust $\chi^{2}$ test was first used to evaluate the correlation between single SNP and GD, and then a common gene model was adopted. Unconditional logistical regression analysis was used to explore the correlation between the SNP allele/genotype and GD. The SHEs is an online software program (http://analysis.bio-x.cn/myAnalysis.php) that was originally used to analyze the leakage of the common CTLA-4 SNPs in the control group.
Pearson's $x^{2}$ test was then used to conduct haplotypic analysis between case and control groups. Multifactor dimensionality reduction (MDR) analysis software was adopted to analyze SNP-SNP interactions.

\section{Results}

Results of the HRM genotyping

Genotyping results of the 10 SNPs are shown in Fig. 1a-j.

Correlation analysis between CTLA-4 and CD40 polymorphism and GD susceptibility

Rs1024161, rs5742909, rs231775, rs231777, rs231779, rs3087243, rs11571319. For the 260 GD patients from the case group and 248 volunteers from the control group, under the conditions of $O R=1.5$ and $\alpha=0.05$, all polymorphic foci had sufficient statistical power to refute the null hypothesis. The Hardy-Weinberg equilibrium test showed that the SNPs rs11571302 and rs11571297 did not match the Hardy-Weinberg equilibrium, and thus they were excluded. All other SNP foci were of good group presentation $(p>0.01)$. After age calibration, the Logistical regression analysis showed that the allelic frequencies of rs231775, rs3087243 and rs1883832 were significantly different between the normal control group and the case group $(P<0.05)$; while the distribution differences of the allelic frequencies of rs231775, rs3087243 and rs1883832 were also significantly different between the normal control group and the case group $(P<0.05$; Tables 3 and 4$)$.

\section{Haplotype analysis for the correlation between CTLA-4 and GD susceptibility}

SNPs rs1024161, rs5742909, rs231775, rs231777, rs231779, rs3087243, and rs11571319 were defined as Site 1-7, respectively. Observations showed a result of $D^{\prime}<50 \%$ and $r^{2}$ $<0.3$ among each SNP of the enrolled seven SNPs, indicating no linkage disequilibrium (LD) among these SNPs (i.e., linkage equilibrium was attained; see Table 5 for the results of the LD analysis).

After excluding the haplotypes with a frequency lower than 0.05 , six commonly found haplotypes remained, and these were named $\mathrm{H}_{1}$ to $\mathrm{H}_{6}$. The $\chi^{2}$ test showed significant differences of $\mathrm{H}_{2}-\mathrm{H}_{6}$ between both groups $(P<0.05)$, with $\mathrm{H}_{3}$ (CCGCCAC) and $\mathrm{H}_{4}$ (TCGCTGC) as the risk factors of GD susceptibility, while $\mathrm{H}_{2}$ (CCACCGC), $\mathrm{H}_{5}$ (TCAC TAC) and $\mathrm{H}_{6}$ (TCACTGC) were described as preventive factors. $\mathrm{H}_{4}$ had the highest risk of susceptibility, while $\mathrm{H}_{5}$ had a maximal preventive effect (see Table 6).

\section{Correlation analysis between SNP-SNP and SNP-sex} interactions of CTLA-4 and CD40 and susceptibility to GD Table 7 lists the study factors and their assignments. The MDR was adopted to analyze the interactions among nine influencing factors (including sex). The data are 
a

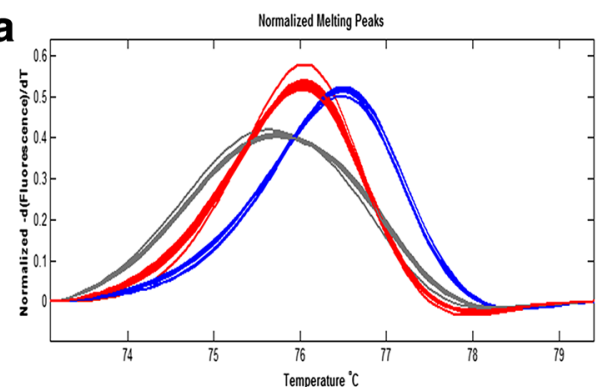

C

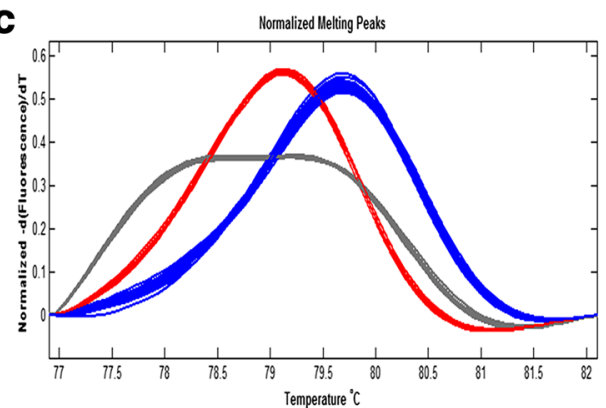

e

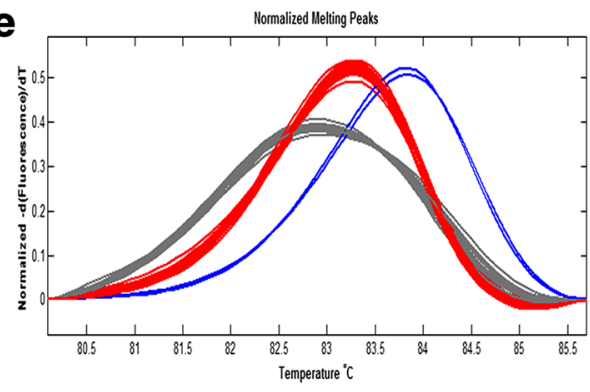

g

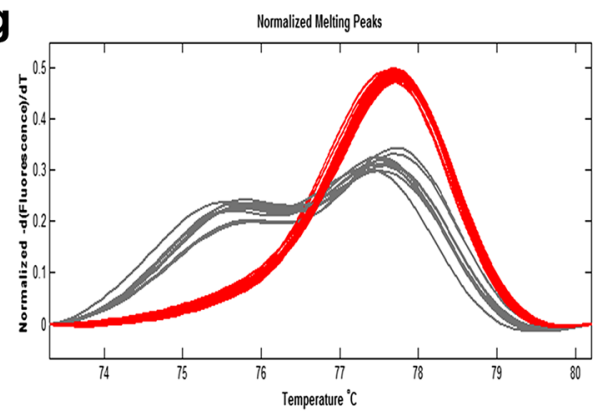

i

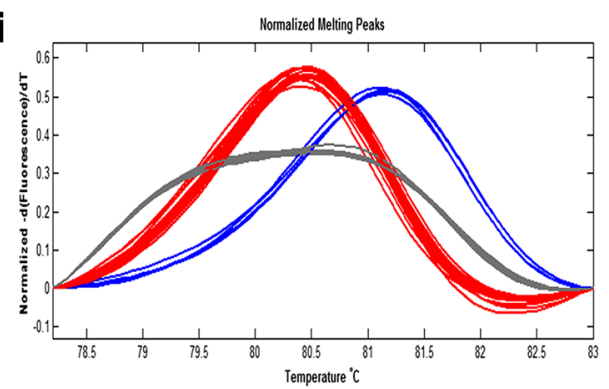

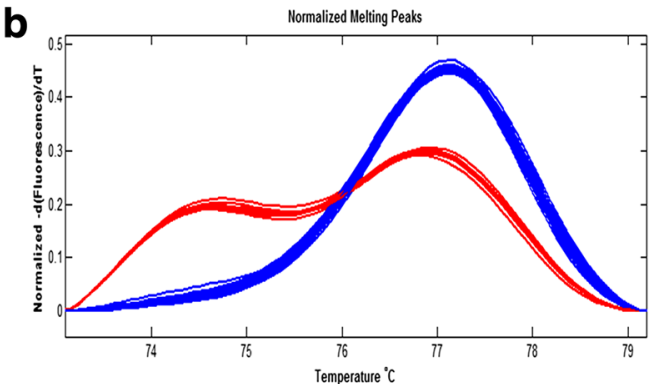

d

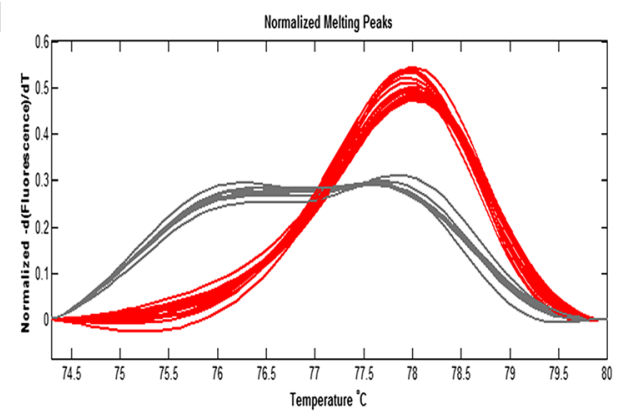

f

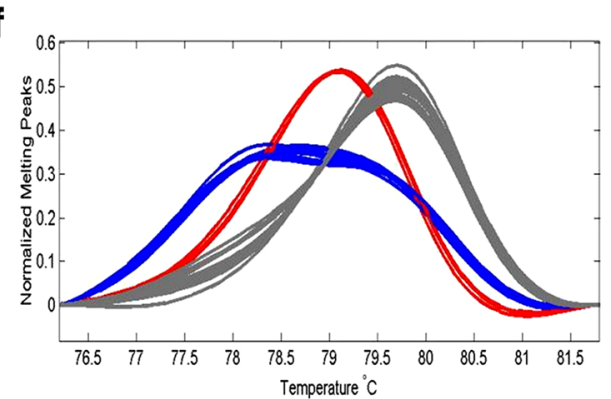

h

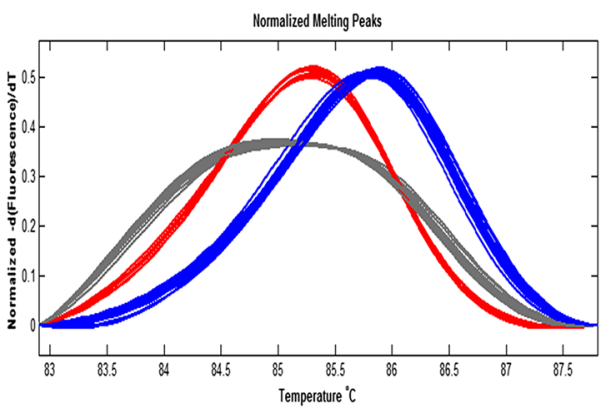

j

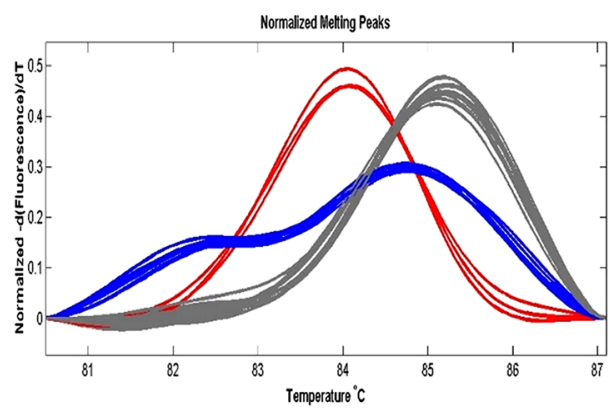

Fig. 1 (See legend on next page.) 
(See figure on previous page.)

Fig. 1 High-resolution standard melting curves of the haplotype analysis. a rs 1024161 melting curve. Blue curve $=\mathrm{CC}$ genotype; red curves $=\mathrm{CT}$ genotype; grey curves = TT genotype. $\mathbf{b}$ rs5742909 melting curve. c rs231775 melting curve. Blue curve = GG genotype; red curve = AG genotype; grey curve $=$ AA genotype. $\mathbf{d}$ rs231777 melting curve. Grey curve $=C$ T genotype; red curve $=C C$ genotype. e rs 231779 melting curve. Blue curve $=C C$ genotype; red curve $=\mathrm{CT}$ genotype; grey curve $=\pi$ genotype. $\mathbf{f}$ rs3087243 melting curve. Grey curve = GG genotype; red curve = AA genotype; blue curve = AG genotype. $\mathbf{g}$ rs11571319 melting curve. Grey curve $=C T$ genotype; red curve $=C C$ genotype. $\mathbf{h}$ rs 11571302. Grey curve $=C A$ genotype; red curve = AA genotype; red curve $=\mathrm{CC}$ genotype. $\mathbf{i}$ rs11571297 melting curve. Grey curve = GA genotype; red curve = AA genotype; blue curve = GG genotype $\mathbf{j}$ rs 1883832 melting curve. Grey curve $=C C$ genotype; red curve $=\Pi$ genotype; blue curve $=C T$ genotype

shown in Table 8. Figure 2 is the graphic model for the three-factor interactions among the SNPs of rs231775, rs231779 and rs3087243. This illustrates that the three-factor interactions among the SNPs of rs231775, rs231779 and rs3087243 exerted a greater impact upon GD susceptibility. By contrast, comparative analysis of individuals with SNPs of rs231775 (A-), rs231779 (C-) and rs3087243 (C-) showed that collaborative SNP-SNP interactions in those individuals expressing SNPs of rs231775 (GG) rs231779 (TT) and rs3087243 (GG) could increase the risk of GD by 2.5 fold $(O R=2.5349)$.

\section{Discussion}

The aim of this study was to perform correlation analyses between GD and CTLA-4 and CD4O haplotypes to understand more about the complex genetic susceptibility of GD. In addition, we have undertaken an in-depth analysis of the interactions between CTLA-4 and CD4O genes in cases of GD as compared to a healthy control group. The results show that CTLA-4 and CD4O are associated with GD incidence in a Chinese Han population and that interactions among rs231775, rs231779 and rs3087243 SNPs significantly increased the susceptibility to GD.

Candidate gene analysis and GWAS have both confirmed that the following genes or regions are susceptible to GD: HLA, CTLA-4, CD40, PTPN-22, FCRL3, 5q31-q33, TSHR and TG [4, 8, 14-20]. Except for HLA, CTLA-4 and CD40 are apparently the most popular susceptibility genes in autoimmune diseases. Meta-analysis has confirmed correlations between the CD40-1C/ $\mathrm{T}(\mathrm{rs} 1883832),+49 \mathrm{~A} / \mathrm{G}(\mathrm{rs} 231775)$ and CT60(rs3087243) polymorphisms and the risk of GD [21, 22]. In this study, our results showed that $C D 40-1 \mathrm{C} / \mathrm{T}(\mathrm{rs} 1883832)$, $+49 \mathrm{~A} / \mathrm{G}(\mathrm{rs} 231775)$ and CT60(rs3087243) polymorphisms were associated with GD risk, but no such correlations were observed in other commonly seen SNPs. The mutant $\mathrm{G}$ allelic frequency of rs231775 was a risk factor of GD susceptibility, while the mutant $\mathrm{A}$ and $\mathrm{T}$ alleles of rs3087243 and rs1883832 were preventive factors. GWAS analysis suggests that SNP rs1024161 is the only CTLA-4 SNP that shows an independent and

Table 3 Correlation analysis between SNP allele and GD susceptibility

\begin{tabular}{|c|c|c|c|c|c|c|c|}
\hline \multirow[t]{2}{*}{ SNP } & & \multirow[t]{2}{*}{ GD group } & \multirow[t]{2}{*}{ Control group } & \multicolumn{2}{|l|}{$P$ value } & \multicolumn{2}{|l|}{$O R(95 \% C l)$} \\
\hline & & & & $x^{2}$ & Logistic & $x^{2}$ & Logistic \\
\hline \multirow[t]{2}{*}{ rs1024161 } & $C$ & 158 & 160 & 0.520 & 0.924 & 0.917 & 0.987 \\
\hline & $\mathrm{T}$ & 362 & 336 & & & $0.703-1.195$ & $0.749-1.300$ \\
\hline \multirow[t]{2}{*}{ rs5742909 } & $\mathrm{T}$ & 52 & 64 & 0.146 & 0.149 & 0.750 & 0.744 \\
\hline & $C$ & 468 & 432 & & & $0.509-1.106$ & $0.498-1.112$ \\
\hline \multirow[t]{2}{*}{ rs231775 } & G & 389 & 328 & 0.002 & 0.001 & 1.521 & 1.593 \\
\hline & A & 131 & 168 & & & $1.159-1.996$ & $1.202-2.112$ \\
\hline \multirow[t]{2}{*}{ rs231777 } & $C$ & 462 & 436 & 0.639 & 0.619 & 1.096 & 1.106 \\
\hline & $\mathrm{T}$ & 58 & 60 & & & $0.747-1.609$ & $0.744-1.645$ \\
\hline \multirow[t]{2}{*}{ rs231779 } & $\mathrm{T}$ & 378 & 360 & 0.968 & 0.987 & 1.006 & 1.002 \\
\hline & $C$ & 142 & 136 & & & $0.763-1.325$ & $0.752-1.336$ \\
\hline \multirow[t]{2}{*}{ rs3087243 } & A & 140 & 187 & $<0.001$ & 0.007 & 0.609 & 0.686 \\
\hline & G & 380 & 309 & & & $0.467-0.794$ & $0.520-0.903$ \\
\hline \multirow[t]{2}{*}{ rs11571319 } & $\mathrm{T}$ & 54 & 60 & 0.388 & 0.562 & 0.842 & 0.887 \\
\hline & $C$ & 466 & 436 & & & $0.570-1.244$ & $0.592-1.329$ \\
\hline \multirow[t]{2}{*}{ rs1883832 } & $\mathrm{T}$ & 234 & 279 & $<0.001$ & $<0.001$ & 0.636 & 0.610 \\
\hline & $C$ & 286 & 217 & & & $0.497-0.815$ & $0.472-0.790$ \\
\hline
\end{tabular}


Table 4 Correlation analysis between SNP genotype and GD susceptibility

\begin{tabular}{llllll}
\hline SNP & Genotype & GD group & Control & \multicolumn{2}{l}{$P$ value } \\
\cline { 5 - 6 } & & & & $x^{2}$ & Logistic \\
\hline rs1024161 & TT/TC/CC & $120 / 122 / 18$ & $120 / 96 / 32$ & 0.034 & 0.162 \\
rs5742909 & TT/TC/CC & $0 / 52 / 208$ & $0 / 64 / 184$ & 0.119 & 0.122 \\
rs231775 & AA/AG/GG & $15 / 101 / 144$ & $32 / 104 / 112$ & 0.007 & 0.006 \\
rs231777 & TT/TC/CC & $0 / 58 / 202$ & $0 / 60 / 188$ & 0.615 & 0.593 \\
rs231779 & $\pi / T C / C C$ & $138 / 102 / 20$ & $136 / 88 / 24$ & 0.569 & 0.898 \\
rs3087243 & AA/AG/GG & $20 / 100 / 140$ & $43 / 101 / 104$ & 0.001 & 0.033 \\
rs11571319 & $\pi / T C / C C$ & $0 / 54 / 206$ & $0 / 60 / 188$ & 0.355 & 0.534 \\
rs1883832 & TT/TC/CC & $58 / 118 / 84$ & $87 / 105 / 56$ & 0.003 & 0.001 \\
\hline
\end{tabular}

powerful correlation with GD; however, our study indicated that rs1024161 might be irrelevant to GD occurrence in the Chinese Han population of Western Guangdong province. However, statistical false negative outcomes that might have been caused by the small sample size could not be ruled out.

GD is a complex disease that is triggered by multiple genes and multiple factors. It is inferred by GWAS that there are over 20 genes that are correlated with GD susceptibility; however, all the currently discovered variations can only explain about $20 \%$ of the causes of genetic susceptibility, and some of them still lack adequate reproducibility in other populations. These facts indicate that there may be more genetic variation that is correlated to GD susceptibility and that need to be screened (including most of the rare variants and copy number variations). In addition, further elucidations of the potential mechanisms and functions of the variations, including gene-gene and gene-environment

Table 5 Linkage disequilibrium test of the commonly found CTLA4 SNPs in the Chinese Han population of Western Guangdong province

\begin{tabular}{lllllll}
\hline D': & Site2 & Site3 & Site4 & Site5 & Site6 & Site7 \\
\hline Site1 & 0.495 & 0.548 & 0.431 & 0.810 & 0.304 & 0.464 \\
Site2 & - & 0.138 & 0.761 & 0.439 & 0.478 & 0.320 \\
Site3 & - & - & 0.391 & 0.512 & 0.120 & 0.391 \\
Site4 & - & - & - & 0.229 & 0.291 & 0.600 \\
Site5 & - & - & - & - & 0.278 & 0.064 \\
Site6 & - & - & - & - & - & 0.419 \\
r2: & Site2 & Site3 & Site4 & Site5 & Site6 & Site7 \\
Site1 & 0.076 & 0.073 & 0.054 & 0.520 & 0.077 & 0.062 \\
Site2 & - & 0.005 & 0.538 & 0.076 & 0.059 & 0.095 \\
Site3 & - & - & 0.041 & 0.051 & 0.013 & 0.041 \\
Site4 & - & - & - & 0.019 & 0.020 & 0.361 \\
Site5 & - & - & - & - & 0.051 & 0.000 \\
Site6 & - & - & - & - & - & 0.042 \\
\hline
\end{tabular}

Table 6 Haplotype analysis for the correlation between CTLA-4 and GD susceptibility

\begin{tabular}{|c|c|c|c|c|c|c|}
\hline & Haplotype & GD \% & Control \% & Fisher's $P$ & Person's $P$ & $\begin{array}{l}\text { OR } \\
(95 \% \text { Cl) }\end{array}$ \\
\hline$\overline{\mathrm{H}_{1}}$ & CCGCCAC & 5.6 & 4.4 & 0.725096 & 0.725093 & $\begin{array}{l}1.109 \\
(0.624-1.969)\end{array}$ \\
\hline $\mathrm{H}_{2}$ & CCGCCGC & 2.0 & 6.0 & 0.000125 & 0.000124 & $\begin{array}{l}0.263 \\
(0.127-0.544)\end{array}$ \\
\hline $\mathrm{H}_{3}$ & CCACCAC & 7.5 & 1.7 & 0.000102 & 0.000101 & $\begin{array}{l}4.056 \\
(1.903-8.646)\end{array}$ \\
\hline $\mathrm{H}_{4}$ & TCGCTGC & 58.6 & 36.2 & $<0.0001$ & $<0.0001$ & $\begin{array}{l}2.565 \\
(1.883-3.495)\end{array}$ \\
\hline $\mathrm{H}_{5}$ & TCACTAC & 1.2 & 9.7 & $<0.0001$ & $<0.0001$ & $\begin{array}{l}0.096 \\
(0.042-0.222)\end{array}$ \\
\hline $\mathrm{H}_{6}$ & TCACTGC & 3.6 & 9.7 & $<0.0001$ & $<0.0001$ & $\begin{array}{l}0.289 \\
(0.166-0.503)\end{array}$ \\
\hline
\end{tabular}

interactions might improve the genetic interpretation of GD susceptibility.

Leakage disequilibrium (LD) analysis was adopted to assess the seven SNPs of the normal Chinese Han population in Western Guangdong province. The results showed $D^{\prime}<50 \%$ and $r^{2}<0.3$ among each SNP, which indicated no LD among these SNPs (i.e., linkage equilibrium was reached). Since there is a high possibility of free gene recombination and allocation, while there is a low possibility of random drift and selection among commonly seen CTLA-4 SNPs in the Chinese Han population of Western Guangdong province, we selected all seven SNPs described above (i.e., rs1024161, rs5742909, rs231775, rs231777, rs231779, rs3087243, rs11571319) so that we could conduct a case-control haplotypic analysis. After excluding haplotypes with a frequency $<0.05$, six haplotypes remained, and the TCGCTGC haplotype was the risk haplotype that displayed the highest frequency, while the TCACTAC haplotype was the preventive haplotype. Risk of GD in individuals with the TCGCTGC haplotype was increased by 2.6 fold while the risk in those with a TCACTAC

Table 7 Study factors and their assignments

\begin{tabular}{|c|c|c|}
\hline & Study factor & Assignment \\
\hline $\mathrm{X} 1$ & sex & "male" = 1; "female" = 2 \\
\hline$\times 2$ & rs1024161 & $\Pi \mathrm{T}=0 ; \mathrm{CT}=1 ; \mathrm{CC}=2$ \\
\hline X3 & rs5742909 & $C C=0 ; C T=1 ; \pi T=2$ \\
\hline$X 4$ & rs231775 & $A A=0 ; A G=1 ; G G=2$ \\
\hline$\times 5$ & rs231777 & $\Pi=0 ; C T=1 ; \pi=2$ \\
\hline X6 & rs231779 & $C C=0 ; C T=1 ; \pi T=2$ \\
\hline X7 & rs3087243 & $\mathrm{GG}=0 ; \mathrm{GA}=1 ; \mathrm{AA}=2$ \\
\hline X8 & rs11571319 & $C C=0 ; C T=1 ; \pi T=2$ \\
\hline \multirow[t]{2}{*}{ X9 } & rs1883832 & $C C=0 ; C T=1 ; T T=2$ \\
\hline & Outcome $(Y)$ & $\mathrm{GD}=1 ;$ healthy volunteer $=0$ \\
\hline
\end{tabular}


Table 8 Multivariate interaction model for GD susceptibility based on MDR analysis

\begin{tabular}{llll}
\hline Model & Bal.Acc.CV Testing & CV. Consistency & $P$ value \\
\hline X1 & 0.617 & $10 / 10$ & 0.0678 \\
X6*X7 & 0.7015 & $10 / 10$ & 0.0013 \\
X4*X6*X7 $^{*}$ & 0.7055 & $8 / 10$ & 0.0023 \\
\hline
\end{tabular}

haplotype was increased by 0.096 fold. Gu et al. [5] analyzed the ACACC and ACGCT haplotypes that were composed of five SNPs in CTLA-4 (i.e., rs4553808, rs5472909, rs231775, rs231777 and rs231779), and discovered that the ACGCT haplotype increased GD risk by 1.6 fold, while the ACACC haplotype reduced the risk by 1.26 fold. Therefore, haplotypes not only break through the limitations of individual SNP analysis, but they can also reduce the difference between studies.

CTLA-4 is undoubtedly one of the susceptibility genes of GD occurrence, but its variations that correlate to the risk of GD differ greatly in different populations. Moreover, in studies that have been conducted on human haplotypes, all known SNPs of a particular gene can be studied in a holistic way, and it is possible to detect tagged SNPs to certain regions of a haplotype, which greatly improves research efficiency, and solves the problem of low testing efficiency that is caused by individual SNP testing, which thus enables us to derive an overall correlation between CTLA-4 and GD [23].

We adopted the MDR model to assess the interactions among nine factors (including sex) and found that three-factor interactions among the SNPs of rs231775, rs231779 and rs3087243 had the greatest impact upon
GD susceptibility. Interactions between rs231779 and rs3087243 exhibited a strong antagonistic effect, but this effect was alleviated after adding rs231775. Both CTLA-4 and $C D 40$ are immunomodulatory genes, but we did not find interactions of CTLA-4 and CD40 that were associated with the risk of GD via MDR analysis. Similarly, Yang et al. [10] also found that there was no multiplied interaction between $C D 40 \mathrm{C} / \mathrm{T}(-1)$ and CTLA-4 A/G (49) SNPs associated with GD susceptibility. However, another study has shown that there may be a combined and additive effect between the CD40-1C $>\mathrm{T}$ and CTLA-4-6230G > A polymorphisms with the development of GD [13]. Other studies have shown that interactions between CTLA-4 and other genes also increased the risk of GD. For example, interactions between HLA-DPB1*0501 and the CTLA4-CT60 polymorphism conferred a 9.99 fold GD risk [24] and synergistic interactions may exist between SNP rs231779 in CTLA-4 and rs2069550 in TG [5]. We therefore infer that the mechanisms of CTLA-4 participating in GD pathogenesis are more complicated than we had originally appreciated, and might involve mechanisms of both intra- and extragenic interactions.

This study has some limitations, including the small sample size that was mentioned above that may have given false negative outcomes. Since we could not determine the major and minor effects of interactions from each level by MDR analysis, we could not differentiate the contributions made by each SNP (i.e., rs231775, rs231779 and rs3087243) to the risk of GD based on interaction analysis. The results only represent statistically related or unrelated, and our results require further

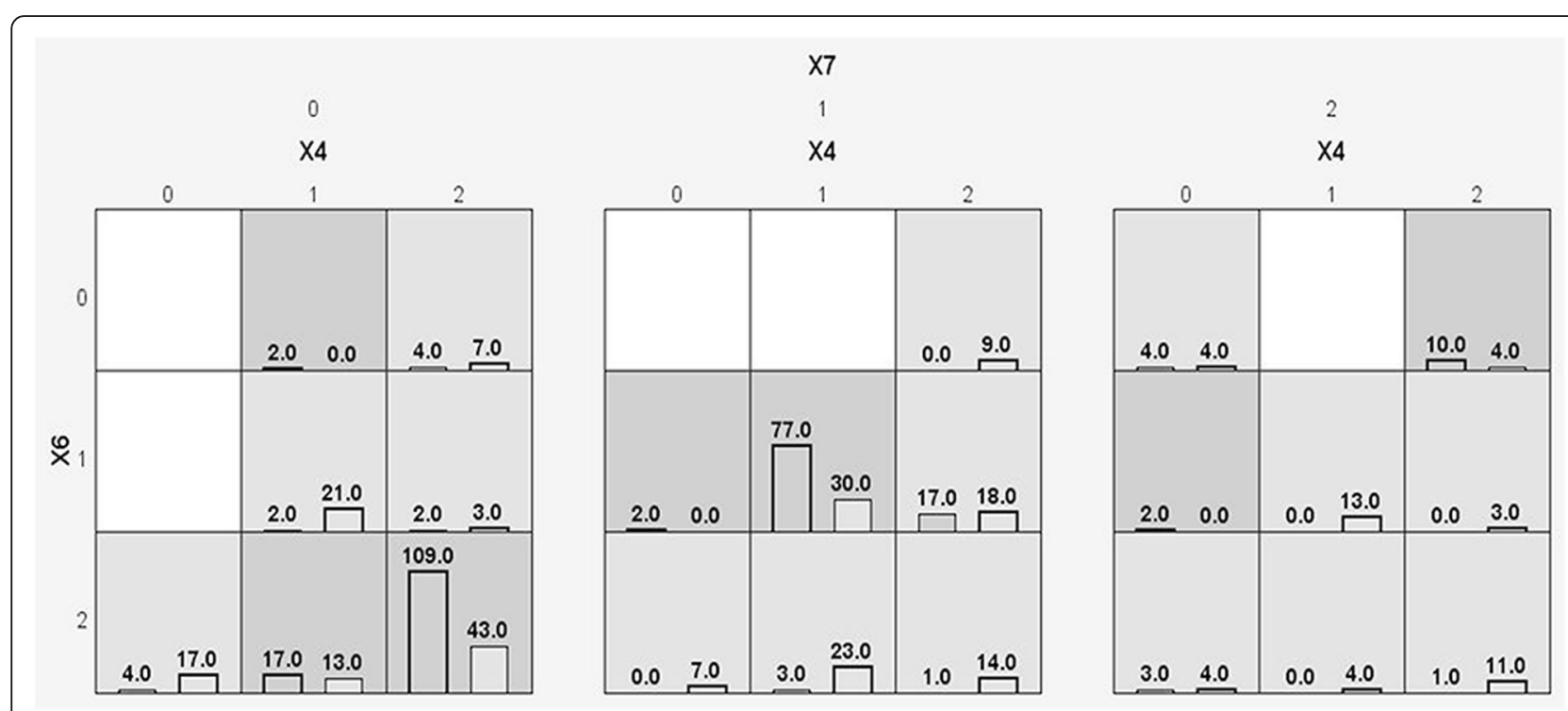

Fig. 2 Graph model for the three-factor interaction among SNPs rs231775, rs231779 and rs3087243. The right side of the grid indicates the GD group and the left side of the grid indicates the healthy control group 
biology. In-depth research in the sense to confirm or correct. All in all, our research is now more precisely a cue for future research than a powerful evidence to clarify the etiology of GD genetics.

\section{Conclusion}

In conclusion, we performed a retrospective case control analysis in the Chinese Han population of the Western Guangdong province (260 GD patients and 248 healthy volunteers), and showed that CTLA-4 and CD4O were correlated with susceptibility to GD. The mutant G allelic frequency of rs 231775 was a risk factor of GD susceptibility, while the mutant $\mathrm{A}$ and $\mathrm{T}$ alleles of SNPs rs3087243 (CT60) and rs1883832 (-1C/T polymorphism) in $C D 40$ were preventive factors. Individuals with a CTLA-4 TCGCTGC haplotype (i.e., rs1024161, rs5742909, rs231775, rs231777, rs231779, rs3087243 and rs11571319) were susceptible to GD, while those with a TCACTAC haplotype were not. Synergistic interactions of the CTLA-4 SNPs rs231775, rs231779 and rs3087243 significantly increased the risk of GD.

\section{Abbreviations}

GD: Graves' disease; GWAS: Genome-wide association studies; LD: Linkage disequilibrium; SNP: Single-nucleotide polymorphism

\section{Funding}

The study was financially supported by grants from the Medical Research Foundation of Guangdong Province, China (grant number A2013432); the Science and Technology planning project Foundation of Guangdong Province, China (grant number 2012B031800489); the Postgraduate Cultivation of Guangdong Medical University, China (grant number YC1201).

\section{Availability of data and materials}

The datasets used and/or analysed during the current study are available from the corresponding author on reasonable request.

\section{Authors' contributions}

XC and ZH carried out the studies, participated in collecting data, and drafted the manuscript. ML and HL performed the statistical analysis and participated in its design. $C L$ and $W L$ performed literature search. $L B$ and $M C$ helped to draft the manuscript. GW provided meaningful discussion key points and given final approval of the version to be published. All authors read and approved the final manuscript.

\section{Ethics approval and consent to participate}

Ethical approval was obtained from the Medical Ethics Committee of the Affiliated Hospital of Guangdong Medical University. The approval number was: PJ2012029. All the above enrolled patients signed an informed consent document.

\section{Consent for publication}

Not applicable.

\section{Competing interests}

The authors declare that they have no competing interests.

\section{Publisher's Note}

Springer Nature remains neutral with regard to jurisdictional claims in published maps and institutional affiliations.
Received: 2 January 2018 Accepted: 14 August 2018

Published online: 17 September 2018

\section{References}

1. Simmonds MJ. GWAS in autoimmune thyroid disease: redefining our understanding of pathogenesis. Nat Rev Endocrinol. 2013;9:277-87. https:// doi.org/10.1038/nrendo.2013.56.

2. Dong YH, Fu DG. Autoimmune thyroid disease: mechanism, genetics and current knowledge. Eur Rev Med Pharmacol Sci. 2014;18:3611-8.

3. Wu S. Membrane Molecule of the Immune Cell. In: Gong FL, editor. Medical Immunology. 3rd ed. Beijing: Science Press; 2012. p. 69-72.

4. Inoue N, Watanabe M, Yamada H, Takemura K, Hayashi F, Yamakawa N, et al. Associations between autoimmune thyroid disease prognosis and functional polymorphisms of susceptibility genes, CTLA4, PTPN22, CD40, FCRL3, and ZFAT, previously revealed in genome-wide association studies. J Clin Immunol. 2012;32:1243-52. https://doi.org/10.1007/s10875-012-9721-0.

5. Gu LQ, Zhu W, Zhao SX, Zhao L, Zhang MJ, Cui B, et al. Clinical associations of the genetic variants of CTLA-4, Tg, TSHR, PTPN22, PTPN12 and FCRL3 in patients with Graves' disease. Clin Endocrinol. 2010;72:248-55. https://doi. org/10.1111/j.1365-2265.2009.03617.x.

6. Farra C, Awwad J, Fadlallah A, Sebaly G, Hage G, Souaid M, et al. Genetics of autoimmune thyroid disease in the Lebanese population. J Community Genet. 2012;3:259-64. https://doi.org/10.1007/s12687-012-0085-1.

7. Namo Cury A, Longui CA, Kochi C, Calliari LE, Scalissi N, Salles JE, et al. Graves' disease in Brazilian children and adults: lack of genetic association with CTLA-4 +49A>G polymorphism. Horm Res. 2008;70:36-41. https://doi. org/10.1159/000129676.

8. Wang $\mathrm{H}$, Jiang $\mathrm{H}$, Liu W. SNP within the $5^{\prime}$ non-encoding region of CD40 is associated with the risk of Grave's disease: a study of the Chinese Han population. Papers Series from the 12th National Endocrinology Conference of the Chinese Medical Association. 2013. p. 119.

9. Tomer Y, Ban Y, Concepcion E, Barbesino G, Villanueva R, Greenberg DA, et al. Common and unique susceptibility loci in graves and Hashimoto diseases: results of whole-genome screening in a data set of 102 multiplex families. Am J Hum Genet. 2003;73:736-47. https://doi.org/10.1086/378588.

10. Yang J, Qin Q, Yan N, Zhu YF, Li C, Yang XJ, et al. CD40 C/T(-1) and CTLA-4 a/G(49) SNPs are associated with autoimmune thyroid diseases in the Chinese population. Endocrine. 2012;41:111-5. https://doi.org/10.1007/ s12020-011-9510-1.

11. Gillespie EF, Raychaudhuri N, Papageorgiou Kl, Atkins SJ, Lu Y, Charara LK, et al. Interleukin-6 production in CD40-engaged fibrocytes in thyroidassociated ophthalmopathy: involvement of Akt and NF-kappaB. Invest Ophthalmol Vis Sci. 2012;53:7746-53. https://doi.org/10.1167/iovs.12-9861.

12. Rudd CE, Taylor A, Schneider H. CD28 and CTLA-4 coreceptor expression and signal transduction. Immunol Rev. 2009;229:12-26. https://doi.org/10. 1111/j.1600-065X.2009.00770.X

13. Chen $X, H u Z$, Li W, Wu P, Liu M, Bao L, et al. Synergistic combined effect between CD40-1C>T and CTLA-4+6230G >a polymorphisms in Graves' disease. Gene. 2015;567:154-8. https://doi.org/10.1016/j.gene.2015.04.074.

14. Chu X, Pan CM, Zhao SX, Liang J, Gao GQ, Zhang XM, et al. A genome-wide association study identifies two new risk loci for Graves' disease. Nat Genet. 2011:43:897-901. https://doi.org/10.1038/ng.898.

15. Gough SC, Simmonds MJ. The HLA region and autoimmune disease: associations and mechanisms of action. Curr Genomics. 2007:8:453-65. https://doi.org/10.2174/138920207783591690.

16. Simmonds MJ, Gough SC. The search for the genetic contribution to autoimmune thyroid disease: the never ending story? Brief Funct Genomics. 2011;10:77-90. https://doi.org/10.1093/bfgp/elq036.

17. Smyth D, Cooper JD, Collins JE, Heward JM, Franklyn JA, Howson JM, et al. Replication of an association between the lymphoid tyrosine phosphatase locus (LYP/PTPN22) with type 1 diabetes, and evidence for its role as a general autoimmunity locus. Diabetes. 2004;53:3020-3.

18. Brand OJ, Lowe CE, Heward JM, Franklyn JA, Cooper JD, Todd JA, et al. Association of the interleukin-2 receptor alpha (IL-2Ralpha)/CD25 gene region with Graves' disease using a multilocus test and tag SNPs. Clin Endocrinol. 2007;66:508-12. https://doi.org/10.1111/j.1365-2265.2007.02762.x.

19. Owen CJ, Kelly H, Eden JA, Merriman ME, Pearce SH, Merriman TR. Analysis of the fc receptor-like-3 (FCRL3) locus in Caucasians with autoimmune disorders suggests a complex pattern of disease association. J Clin Endocrinol Metab. 2007;92:1106-11. https://doi.org/10.1210/jc.2006-2183. 
20. Brand OJ, Barrett JC, Simmonds MJ, Newby PR, McCabe CJ, Bruce CK, et al Association of the thyroid stimulating hormone receptor gene (TSHR) with Graves' disease. Hum Mol Genet. 2009;18:1704-13. https://doi.org/10.1093/ hmg/ddp087.

21. Du L, Yang J, Huang J, Ma Y, Wang H, Xiong T, et al. The associations between the polymorphisms in the CTLA-4 gene and the risk of Graves' disease in the Chinese population. BMC Med Genet. 2013;14:46. https://doi. org/10.1186/1471-2350-14-46.

22. Hu Z, Chen X, Li W. The association between the polymorphisms in the CD40 gene and Graves' disease: a Meta analysis. Chongqing. Medicine. 2015:11:4544-52.

23. Zhao SX, Xue LQ, Liu W, Gu ZH, Pan CM, Yang SY, et al. Robust evidence for five new Graves' disease risk loci from a staged genome-wide association analysis. Hum Mol Genet. 2013;22:3347-62. https://doi.org/10.1093/hmg/ddt183.

24. Takahashi M, Kimura A. HLA and CTLA4 polymorphisms may confer a synergistic risk in the susceptibility to Graves' disease. J Hum Genet. 2010;55: 323-6. https://doi.org/10.1038/jhg.2010.20.

Ready to submit your research? Choose BMC and benefit from:

- fast, convenient online submission

- thorough peer review by experienced researchers in your field

- rapid publication on acceptance

- support for research data, including large and complex data types

- gold Open Access which fosters wider collaboration and increased citations

- maximum visibility for your research: over $100 \mathrm{M}$ website views per year

At $\mathrm{BMC}$, research is always in progress.

Learn more biomedcentral.com/submissions 